\title{
The Reconstruction Design of Theme Park: A Study on Floraland Centre Island of Chengdu \\ Qian Li ${ }^{1, a}$, Yuanzhi Pan ${ }^{1}$ \\ ${ }^{1}$ Sichuan Agricultural University, Chengdu, Sichuan Province, China \\ a75262818@qq.com
}

Keywords: Image Promotion, Landscape Reconstruction, Theme Park.

\begin{abstract}
The reconstruction of Centre Island is an important part of Floraland theme park of Chengdu. Based on its current status and reconstruction requirements, the theme direction and style of reconstruction have been settled. By updating the architectural form, refining its theme elements and reconstructing spatial layout, the regional image of this Centre Island has been improved, which makes it a significant visiting spot within the park. This also provides the tourists with different spatial and environmental perceptions and contributes to the formation of a new landscape which is symbiotic with its surrounding theme areas.
\end{abstract}

\section{The Current Status of Centre Island and Its Problems}

Theme parks refer to those leisure and entertainment parks with certain themes and the purpose of gaining profit. They are artificially created landscapes and recreational facilities which help the tourists get special experience. Theme parks are generally designed around one or more themes. Floraland theme park of Chengdu is located in Wanchun Town, Wenjiang Distract. Since its opening in 2007, it has become the major theme park in Sichuan Province and neighboring provinces. Centre Island involved in this paper is located in the center of this park with a design area of $9946 \mathrm{~m} 2$, which is an important landscape within the park. Over time, the island' s original amusements cannot meet the tourists' diverse requirements. The main problems in this region are unclear amusement theme, unclear functional details, thick plants, disorder landscapes, unclear tour lines and road systems, destroyed resting facilities and blurring revetment borders, etc. These problems has made this highly respected them park forgotten by the tourists. Therefore, the improvements of Centre Island are expected. How to reconstruct and design an attractive and distinctive landscape based on the original conditions has become a major issue of in this case.

\section{Reconstruction Design Strategies}

Centre Island within Floraland park is an independent artificial island. It has different themes in surrounding water areas. Thus, the image of this island needs to be consistent with its surrounding environment. Combined with specific circumstances, we work out the reconstruction design with the theme of genie. This involves the plants, the architectres, paving, revetment and facilities within this island, as well as the color update of recreational facilities. Through the reconstruction and design of ladscape with contemporary style, we reshape the theme image of the island and improve its overall design. The specific design strategy include the following two aspects.

Strengthened topic. ZHANG Guang-rui proposed that theme is the soul of theme parks and innovation is its life [1]. To enhance the expressiveness of the theme park, the theme design of Centre Island need to be strengthened. The original landscapes inside the island are mainly statically presented. The tourists are attracted to those dynamic activities and entertament within. And because of the low participation, the static landscapes are easily overlooked. During the reconstruction design, the clear themes of fairy tales and some expressive colors will impress the tourists. By adopting various types of landscape elements with the features of theme symbols, the tourists can participate in landscape interaction and it will improve the recognition and identification of sites, which will enhance the tourists' recognition of Centre Island image. 
Space reconstruction. The tourists are expected to behavior according to the design guidance. Firstly, it can ensure that more people will use the public space. Secondly, it will encourage everyone to stay longer. [2] The original plants in this island lush grow well and form a hermetically enclosed space (Figure 1). Thus, there are few tourists. Through site analysis (Figure 2), the space is redesigned, forming an organic combination of semi-open space and open space, which ultimately change the tourists' behaviors. The south of the island is cloased to water. Thus, the existing bushy plants are transplanted, which will allow sunlight to penetrate into the island. Due to the wide vision, sun lawn is palced in Merry-go area. Therefore, even if staying in surrounding areas, the tourists can see the amusements within the island, which attracts the tourists to enter into the island. In the part of revetment, some of the existing plants are simplifid. And through the road system design with various forms, the level of tour space has been enriched.

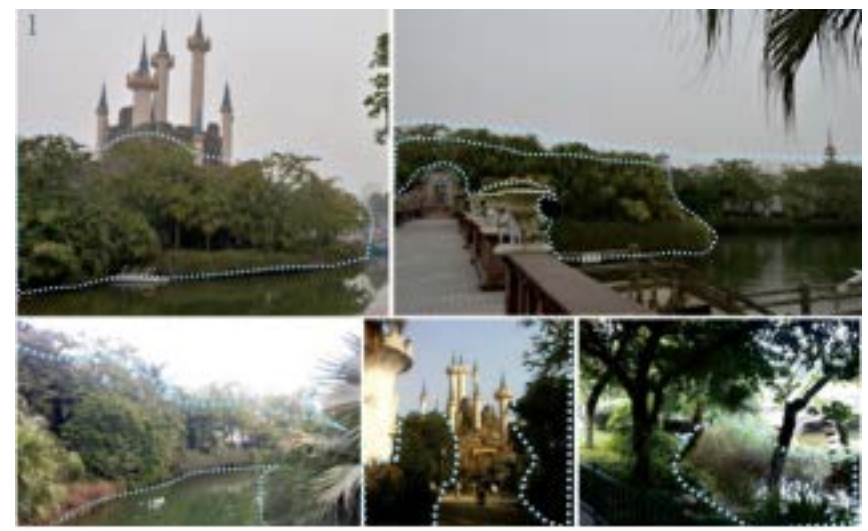

Figure 1 Shape of the space
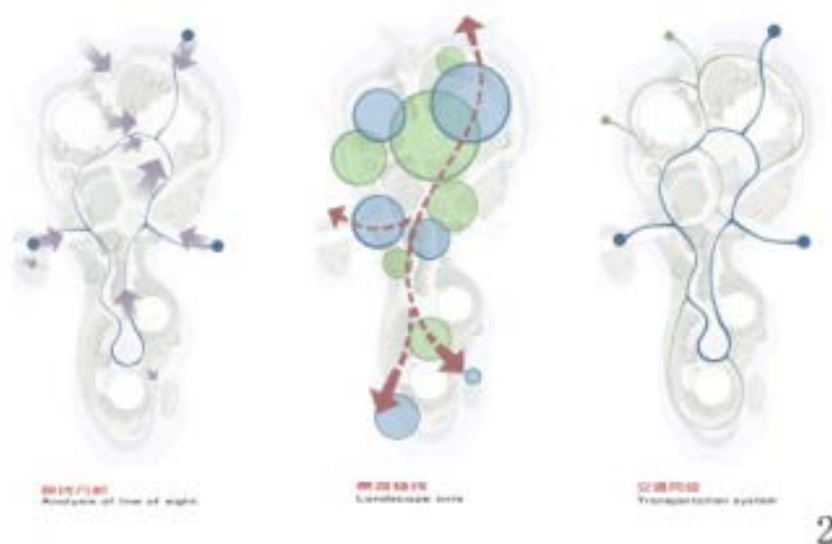

Figure 2 Analysis of vision, axial line and transportation

\section{The Main Contents of Reconstruction Design}

According to the present field status and reconstruction requirements, the following reconstruction design of Centre Island is worked out.

Redesign of castle. There are two castles in the island has. The castle of genie is a main building and key reconstruction site of Centre Island areas, as well as an important landscape which attracts the tourists. We focus on the theme of genie and change the original height of buildings and the structure of space, so that the tourists have more experience while participating in the activities of the castle. Through a variety of castle themes, the tourists' visual impression of the castle has been deepened. The height difference of landscapes will cause lookout compensation, which will meet the requirements of the tourists. By adding interactive space, it will meet the needs of more diverse tour and promote commercial consumption. With different themes and various recreational activities, it will attract more tourists and promote the tourism of this island. Through the reconstruction of the 
height of the buildings, plants and recreational facilities within the island, it forms a new skyline. The visual image of Centre Island has been changed by new visual effects (Figure 3).

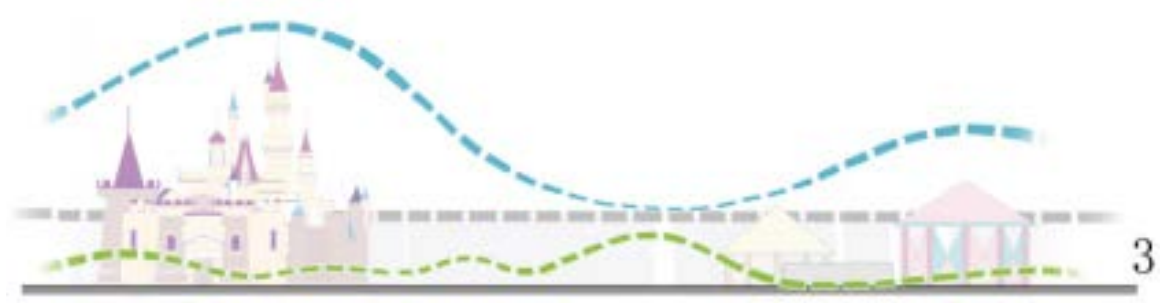

Figure 3 The height of buildings, plants and entertainment facilities

Configuration of plants. There are various plants in this island. However, the canopy line of the arbor plants lack morphology features. In the reconstruction, we transplant the irregular trees to enhance the tall trees around the castle make the image of the theme park the visual focus in its surrounding theme areas facing Centre Island. In addition, the vegetations with middle-level height are reasonably liquidated, highlighting the image of the castle. In the north exit of the castle, we set micro topography and sun lawn. The tall washingtonia filifera with long-time growth in east entrance have been reserved. The messy yucca elephantipes in the back of the castle have been removed and wodyetia bifurcate have been added. Some plants near the water have been removed to enlarge the space of lawn, such as, bauhinia variegate, Philodenron selloum Koch, Jasminum mesnyi, Jacaranda mimosifolia D. Don, Scutellaria sessilifolia Hemsl. The bushes have been replanted. We retain and plant more bushes which are easy to trim, such as, Syringa tomentella, Loropetalum chinense var.rubrum. These are made some ball-shaped plants. In terms of the theme of genie, we trim the plants into different shapes, square, ball and trapezium to meet the requirements of different themes. Cycas revoluta Thunb and Livistona chinensis with good shape have been retained to complement theme of seasonal flowers. Through the above details, not only we can use the plants to provide people with better landscape vision, but also the plants in the island can get plenty of light. Meanwhile, Poa annua, Lolium perenne L. and Procumbent juniper are respectively used to make lawn with different color levels. After reconstruction, the sight of the whole island is transparent. The configuration of plants with different height is clear. The visual form of beauty has been dramatically increased.

Resting corridor. Resting corridor is the only way to the castle and entertainment facilities. It is the most important traffic area. The park is a theater, and each activity is a potential stage. [3] We put resting chairs without back along the road, which will meet more tourists' requirement of resting and catching eye of each entertainment district. In this way, we can handle the relationship between the tourists' to see and be seen. According to the climatic conditions in Chengdu, we retain ficus microcarpa with larger diameter and provide the tourists with an open space of rest and cool air. In the reconstruction of road, we mainly use the basic design element of curve to widen the road and make the borders soft. We also dismantle the existing fence and adopt the road borders with a natural texture and some seasonal flowers and plants, which not only enhances the scene and performance of the fairy tale theme, but also improves the ventilation and natural light of resting area.

Reconstruction of revetment. The boundary water areas of Centre Island can interact with the surrounding theme parks. It is an important image presentation area of the island, as well as another key area in this reconstruction. In terms of the sense of the overall form, we remove some luxuriant plants around the water, such as Murraya paniculata. We also adopt natural stones in the border part of revetment and water. By using the revetment form of grassy slopes into the water, we make the borders soft and enhance the affinity of landscapes, which forms a better landscape. In addition, the natural stones are used to pave the road to the recreation area, which meets the tourists' requirement of closing to the water and increase the interactive fun of space. 


\section{Main Features of Design Proposal}

Style design of plants. In the design area, we select the cute animals, plants and genie cartoon images to express the theme of fairy tale in this area. In the water area outisde of Centre Island, we set marine animal images. And in the water area inisde of Centre Island, we choose the animal images which can reflect the themes, as well as some sculptures in the image of genies. With ligustrum quihoui, we make the modeling frameworks of dolphins, ducks and cartoon characters. We use certain lashing methods to cultivate plant styles, which contributes to the harmony of plant images and the entire landscapes within the theme park and achieves the ecologization of artistic expression. The vegetation in shapes of pillars and balls have also reflect the world of fairy tales and enrich the visual forms of the landscapes. (Figure 4)

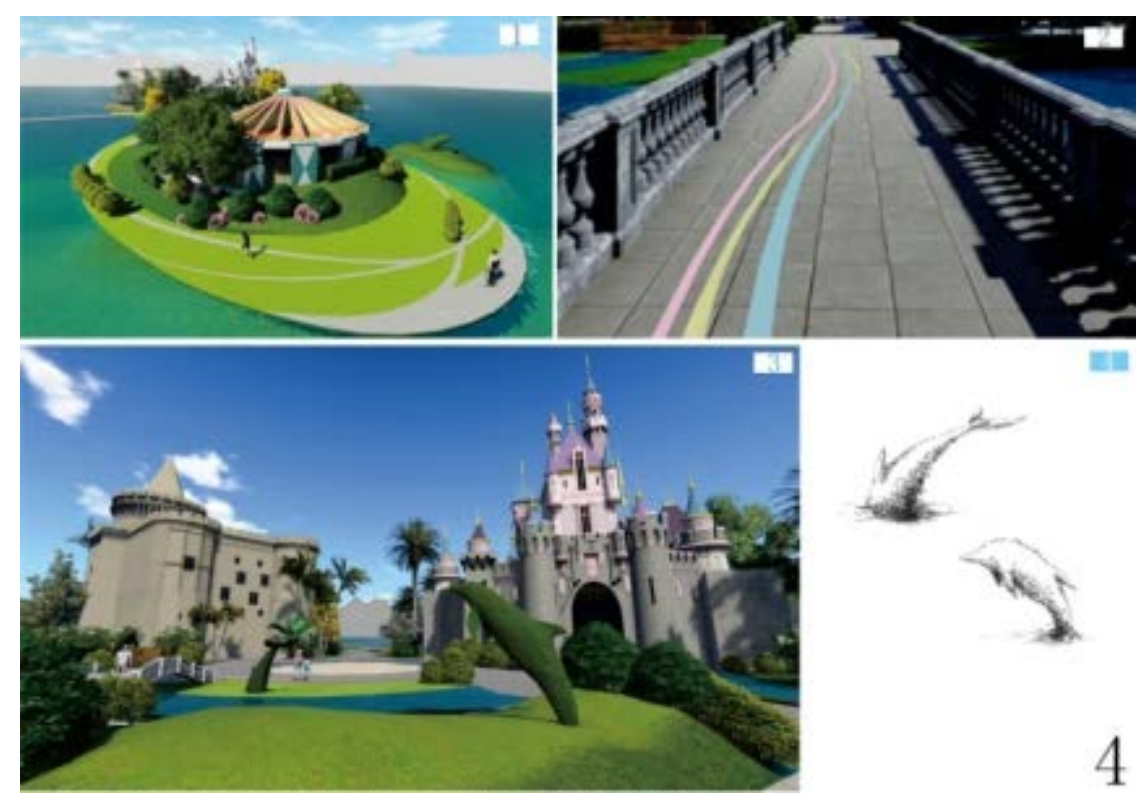

Figure 4: 4.1 Area of revetment and recreation 4.2Ground of the west entrance 4.3Castal area 4.4 Molding plant

Design of road system. The east and west entrances is across the island, forming the shortest line which is access to the opposite subject areas. During the reconstruction, the wall of the west entrance is removed. We plant some structured type of hedge with a declining trim from the north and south. Three-dimensional space modeling is also set to hide the east channel. Therefore, the island' $\mathrm{s}$ population will be naturally triaged realize the rationalization of moving tourism line around the island. The tourists will also avoid the phenomenon of duplication and turning back. All these will enhance the tourists' overall perception and the utilization of space.

Color design. The leaders of this theme park demand to retain the original floor coverings during the reconstruction. From the beginning of extracting elements (Figure 5 and Figure 6), we combine the theme of genie and the traces across the sky is adopted in the ground color design, allowing the tourists to follow the guidance of different ground color lines. The tourists' curiosity will also be inspired, which meets their psychological requirements of the fairy tale world. The recreational facilities within the design area, such as Cups and Saucers, carousel, and the associated ticket booth, waiting areas and so on, have out-of-date colors and lack the sense of times. Thus, based on the colors of ground and the top of the castle, we redesign the colors which can reflect the theme and choose a breathable, waterproof and corrosion-proof coating. Through the fine spray, we create a relaxed, dreamy and pleasant color, which will emphasize the spirit of space and deepen the tourists' overall experience of regional landscape. 


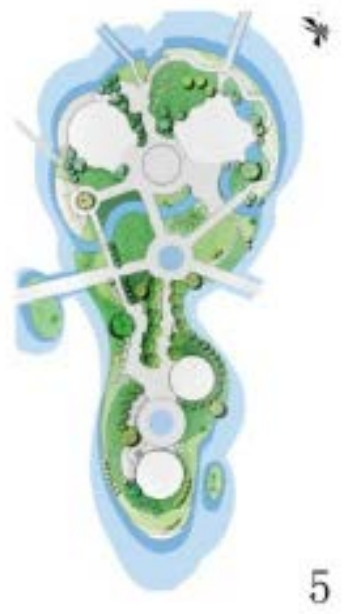

Figure 5 Planar graph
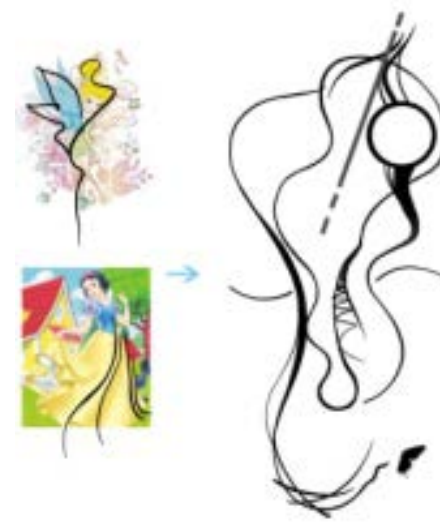

Figure 6 Element extraction

\section{Conclusions}

Theme Park is some kind of landscape during urban development. Its landscape and theme would be changed with time and be improved with people' $s$ requirements. Therefore, its reconstruction and redesign naturally follow. Centre Island is a part of Floraland theme park, as well as a separate area with a clear theme. Its reconstruction has the commonality of ordinary theme parks, as well as independent personality. Only sufficiently emphasizing and improving its theme in different design areas, would we clear the particularity and place spirit of the theme park. Meanwhile, during the reconstruction design, we make the best use of the existing resources and emphasis on the usage of low-carbon or renewable resources. Thereby, the case has not only highlighted in green design and eco design, but also made Centre Island full more charming.

\section{Acknowledgement}

Fund Project: This project is supported by Foundation for Landscape Art Design of the research centre of Education Department of Sichuan Province (Project No.: 640Z2300) and Foundation for Art Development of Sichuan Agricultural University (Project No.: 06208116). Team of design: LI Qian, PAN Yuan-zhi, CHEN Yue-bo, WANG Qian-ying, LI Hong-ping, WANG Xiao-yu.

\section{References}

[1] ZHANG Xiao-zhen. The Current Problems of Domestic Theme Parks and Its Development Strategies [J]. ECONOMIC RESEARCH GUIDE, 2009 (12): 148-149.

[2] Jan Gehl. Interpreted by XU Ren-ke. Life Between Buildings [M]. Beijing: China Architecture \& Building Press, 2002 (The 4th edition): 69.

[3] Albert J.Rutledge. Interpreted by WANG Qiu-shi \& GAO Feng. A Visual Approach to Park Design [M]. Beijing: China Architecture \& Building Press, 1990: 12. 